TEIXEIRA, Elisângela Sampaio; FERRARI, Roseane. O papel do município na concretização dos direitos fundamentais sociais. Revista Eletrônica Direito e Política, Programa de Pós-Graduação Stricto Sensu em Ciência Jurídica da UNIVALI, Itajaí, v.10, n.3, 20 quadrimestre de 2015. Disponível em: www.univali.br/direitoepolitica - ISSN 1980-7791.

\title{
O PAPEL DO MUNICÍPIO NA CONCRETIZAÇÃO DOS DIREITOS FUNDAMENTAIS SOCIAIS
}

\author{
THE PAPER OF THE MUNICIPALITY ON THE REALIZATION OF \\ FUNDAMENTAL SOCIAL RIGHTS
}

\section{Elisângela Sampaio Teixeira ${ }^{1}$ \\ Roseane Ferrari}

SUMÁRIO: Considerações Iniciais; 1 . Os direitos fundamentais sociais, contexto histórico e objeto; 2. O município brasileiro e as possibilidades de concretização dos direitos sociais; Considerações finais; Referências das fontes citadas.

\section{RESUMO}

A Constituição Federal de 1988 concedeu ao Município brasileiro um plexo de autonomias sem precedentes na história brasileira. Levando em consideração a importância dada pelo constituinte a este ente federativo, a presente pesquisa tem como objetivo tecer breves apontamentos sobre a importância do município no cumprimento dos direitos fundamentais sociais. Para tanto, inicialmente, passa por um breve histórico dos direitos sociais, posteriormente adentra nas autonomias municipais e incentivos estatais que possibilitam o cumprimento de tais direitos. Constata-se, ao final do trabalho, que quanto mais consciência por parte do parlamento municipal e do poder executivo sobre as autonomias municipais e sobre a importância de uma boa governança, transparente, participativa e ainda, com o cumprimento da Lei de Responsabilidade Fiscal, mais o município concretiza os direitos sociais.

PALAVRAS-CHAVE: Governança Pública; Município; Direitos Sociais.

\section{ABSTRACT}

The 1988 Constitution gave the Brazilian municipality unprecedented autonomy plexus in Brazilian history. Considering the importance given by the constituent to

\footnotetext{
${ }^{1}$ Mestranda em Direito pelo Programa de Pós Graduação da Faculdade de Direito da Universidade de Passo Fundo-UPF. Bolsista Capes. Advogada. E-mail: elisangelateixeira.adv@gmail.com

${ }^{2}$ Mestranda em Direito pelo Programa de Pós Graduação da Faculdade de Direito da Universidade de Passo Fundo-UPF. Bolsista Capes. Advogada. E-mail: roseane_ferrari@hotmail.com.
} 
TEIXEIRA, Elisângela Sampaio; FERRARI, Roseane. O papel do município na concretização dos direitos fundamentais sociais. Revista Eletrônica Direito e Política, Programa de Pós-Graduação Stricto Sensu em Ciência Jurídica da UNIVALI, Itajaí, v.10, n.3, 20 quadrimestre de 2015. Disponível em: www.univali.br/direitoepolitica - ISSN 1980-7791.

this federative entity, this research aims to make brief notes about the importance of the city in compliance with fundamental social rights. Therefore, initially goes through a brief history and concept of social rights, then enters in state and municipal incentives autonomies that enable the fulfillment of these rights. It appears at the end of work, the more awareness on the part of the municipal parliament and the executive power over municipal autonomy and the importance of good governance, transparency, participation and also to compliance with the Fiscal Responsibility Law, plus the municipality implements social rights.

KEYWORDS: Public Governance; Municipality; Social rights.

\section{CONSIDERAÇÕES INICIAIS}

O presente trabalho tem como objetivo tecer algumas considerações sobre a relevância da atuação do município na concretização dos direitos sociais. O município é o ente federado mais próximo da realidade e necessidades diárias das pessoas, devendo, através da boa governança realizar políticas públicas eficientes e utilizar-se do pleno uso de suas autonomias para assim concretizar e promover os direitos sociais.

Tais direitos interessam as pessoas, possibilitam sua autonomia, liberdade e cidadania e se caracterizam pelas necessidades básicas tal como obter um trabalho, uma habitação, ter acesso à saúde, a alimentação e a educação.

Canotilho explica que após a superação do Estado Liberal de Direito e com o advento do Estado do bem-estar social, os direitos fundamentais passam para além de uma concepção individual, ou seja, passam a ser reconhecido também o dever de tutelar a "proteção e à materialização de bens considerados importantes para a comunidade" ${ }^{\prime 3}$.

Neste sentido, complementa Pisarello ${ }^{4}$ que os direitos sociais tornaram-se essenciais para dar liberdade real tanto na esfera privada do ser humano quanto

\footnotetext{
${ }^{3}$ CANOTILHO, José Joaquim Gomes. LEITE, José Rubens Morato. Direito constitucional ambiental brasileira. 3. ed. São Paulo, SP: Editora Saraiva, 2010, p.215.

4 PISARELLO, Geraldo. Los derechos sociales y sus garantías. Elementos para una reconstrucción. Madrid: Editorial Trotta, 2007, p. 45.
} 
TEIXEIRA, Elisângela Sampaio; FERRARI, Roseane. O papel do município na concretização dos direitos fundamentais sociais. Revista Eletrônica Direito e Política, Programa de Pós-Graduação Stricto Sensu em Ciência Jurídica da UNIVALI, Itajaí, v.10, n.3, 20 quadrimestre de 2015. Disponível em: www.univali.br/direitoepolitica - ISSN 1980-7791.

na esfera pública e podem ser vistos e vinculados ao direito a liberdade, explica o autor sobre os direitos sociais:

"Entendida, de hecho, como el conjunto de recursos que
capacita a las personas para participar en la vida social y
escoger planes de vida próprios, la noción de libertad está
estrechamente ligada a la de pluralismo y diversidade
cultural. En consecuencia, resulta difícil no ver a todos los
derechos civiles, políticos y sociales como derechos fundados
en la necesidad de satisfacer el más amplio derecho a la
igual libertad y a la igual diversidade de todas las
personas."

Destarte, os direitos sociais concretizam a autonomia dos planos de vidas das pessoas e proporcionam mais liberdade e igualdade. Para a concretização de tais direitos a Constituição Federal de 1988 possibilitou em seu artigo art. 30, I que o município tem competência para legislar sobre assunto de interesse local possuindo autonomias para concretizar as políticas públicas definidas pelo poder executivo e legislativo juntamente com a sociedade organizada.

Para desenvolver o trabalho, utilizou-se o método de pesquisa teórica ${ }^{6}{ }^{7}$ através da qual se analisou conteúdo das leis, consulta de livros e jurisprudências pertinentes ao assunto.

\section{OS DIREITOS FUNDAMENTAIS SOCIAIS, CONTEXTO HISTÓRICO E OBJETO}

Ao tratar-se de direitos sociais é preciso compreender o contexto histórico que levou à conscientização da necessidade de intervenção do Estado a conduzir e efetivar tais direitos.

\footnotetext{
5 PISARELLO, Geraldo. Los derechos sociales y sus garantías. Elementos para una reconstrucción, 2007, p. 49.

${ }^{6}$ GUSTIN, Miracy Barbosa de Souza. DIAS, Maria Tereza Fonseca. (Re)pensando a pesquisa jurídica: teoria e prática. Belo Horizonte, BH: Editora Del Rey, 2010, p.106.

7 BASTOS, Cleverson Leite. KELLER, Vicente. Aprendendo a aprender: introdução à metodologia científica. Petrópolis, RJ: Editora Vozes, 2008, p.60.
} 
TEIXEIRA, Elisângela Sampaio; FERRARI, Roseane. O papel do município na concretização dos direitos fundamentais sociais. Revista Eletrônica Direito e Política, Programa de Pós-Graduação Stricto Sensu em Ciência Jurídica da UNIVALI, Itajaí, v.10, n.3, 20 quadrimestre de 2015. Disponível em: www.univali.br/direitoepolitica - ISSN 1980-7791.

O marco histórico deste contexto passa pela Revolução Industrial, ocorrida entre os séculos XVIII e XIX, que proporcionou diversas mudanças sociais e teve como principal característica a substituição da mão de obra artesanal pelo trabalho assalariado e uso de máquinas. ${ }^{8} \mathrm{~A}$ revolução industrial trouxe desenvolvimento econômico à sociedade, produção em massa, novas formas de pensar administrativamente, todavia, como consequência houve sobra de mão de obra, já que as máquinas passaram a substituir milhares de trabalhadores.

O excesso de pessoas e a escassa oportunidade para inseri-las as no trabalho possibilitou a exploração sem limites da mão de obra. Trata-se de um período de opressão aos trabalhadores e consumidores que viviam sem o mínimo de direitos sociais, afinal, o lucro era o foco principal dos empregadores e o Estado não intervinha na economia devido a política liberal.

O bem estar dos trabalhadores e suas condições de vida, seu bem estar não era tutelado nem pelo Estado nem mesmo fazia parte da filosofia empresarial daquela época.

Explica Bertanello que com "o avanço do capitalismo, os trabalhadores viram-se compelidos a empregarem-se nas fábricas, sem garantias condignas com a dignidade da pessoa humana." 9

Não havia diferença protetiva de patrão e empregado, todos eram iguais, não havia uma percepção de que o poder econômico poderia ser o elo mais forte desta relação.

É no século XIX que os direitos sociais ganham destaque como consequência das exigências pleiteadas pelas classes trabalhadoras frente aos clássicos direitos individuais.

${ }^{8}$ Revolução industrial. Portal de comunicação professore e aluno - PRAL. Porto Alegre, RS. Disponível em: http://www.sohistoria.com.br/resumos/revolucaoindustrial.php. Acesso 05/04/2015.

${ }^{9}$ BERTRAMELLO, Rafael. Os direitos sociais: conceito, finalidade e teorias. Jusbrasil. Jun. 2014. Disponível em: http://rafaelbertramello.jusbrasil.com.br/artigos/121943093/os-direitos-sociaisconceito-finalidade-e-teorias. Acesso 02 de abril de 2015. 
TEIXEIRA, Elisângela Sampaio; FERRARI, Roseane. O papel do município na concretização dos direitos fundamentais sociais. Revista Eletrônica Direito e Política, Programa de Pós-Graduação Stricto Sensu em Ciência Jurídica da UNIVALI, Itajaí, v.10, n.3, 20 quadrimestre de 2015. Disponível em: www.univali.br/direitoepolitica - ISSN 1980-7791.

Complementa Sarlet ${ }^{10}$ que o impacto da industrialização e os graves problemas sociais e econômicos fez com que trabalhadores exigissem do Estado uma posição ativa na proteção dos trabalhadores e cidadãos, percebeu-se a necessidade do Estado ser o responsável pela realização da justiça social.

Afirma o referido autor: "Não se cuida mais de evitar a intervenção do Estado na esfera da liberdade individual, mas, sim, na lapidar formulação de C. Lafer, de propiciar um "direito de participar do bem-estar social."'11

Ou seja, neste momento se percebe que a liberdade poderia se dar através do Estado, este não poderia mais seguir as ideias liberais de total liberdade de mercado, mas sim, atuar na defesa dos cidadãos, intervir na proteção para que pudesse evitar abuso por parte do poder econômico.

Sob outro prisma, Pisarello ${ }^{12}$ afirma que a história moderna dos direitos sociais se inscreve em um largo século que começa com as grandes revoluções sociais de meados do século XX evolui e se estabiliza até a segunda guerra.

Todavia o autor afirma que antes do século XX já se falava em direitos sociais e chama esse momento de "pré história dos direitos sociais", onde é possível detectar tanto políticas institucionais dirigidas a resolver situações de pobreza e exclusão social como de lutas pela subsistência e seguridade material. Esta pré história se remonta a muito antes do surgimento do Estado Moderno e guarda um ar familiar com algumas reivindicações contemporâneas em matéria de direitos sociais. ${ }^{13}$

Tanto a antiguidade como a idade média existiram diferentes mecanismos institucionais, ainda que não necessariamente estatais, orientados a amenizar as situações de pobreza e a assistir aos mais necessitados, cita-se como exemplo a

10 SARLET, Ingo Wolfgang. A eficácia do direitos fundamentais: uma teoria geral dos direitos fundamentais na perspectiva constitucional, $11^{\circ}$ edição, livraria do advogado, 2012, p.47

11 SARLET, Ingo Wolfgang. A eficácia do direitos fundamentais: uma teoria geral dos direitos fundamentais na perspectiva constitucional, 2012, p.47

12 PISARELLO, Geraldo. Los derechos sociales y sus garantías. Elementos para una reconstrucción. Madrid: Editorial Trotta, 2007.

13 PISARELLO, Geraldo. Los derechos sociales y sus garantías. Elementos para una reconstrucción, 2007, p. 49. 
TEIXEIRA, Elisângela Sampaio; FERRARI, Roseane. O papel do município na concretização dos direitos fundamentais sociais. Revista Eletrônica Direito e Política, Programa de Pós-Graduação Stricto Sensu em Ciência Jurídica da UNIVALI, Itajaí, v.10, n.3, 20 quadrimestre de 2015. Disponível em: www.univali.br/direitoepolitica - ISSN 1980-7791.

lei dos pobres de 1601 na Inglaterra, como forma de dar assistência aos mais necessitados.

Todavia, apesar de Pisarello colocar que há sim uma construção ao logo diversos séculos dos direitos sociais, principalmente na europa, Luño explica que os direitos sociais são introduzidos nas constituições de vários países em períodos muito próximos, cita:

(...) la constitución Mexicana de 1917, a la Constitución de Weimer de 1919, y a partir de entonces muchos otros textos como la Constitución Española de 1931, la francesa de 1946, la italiana 1947, la alemana en 1949, la Constitución de Grecia de 1975, la carta magna de Portual de 1976 y la Espanã de $1978 .^{14}$

Ou seja, foi através da introdução dos direitos sociais nas constituições de diversos países que demostra uma maior consciência sobre a necessidade de tutelar tais direitos.

Neste sentido Sarlet ${ }^{15}$ afirma que os direitos sociais também possuem um forte vínculo com a dignidade da pessoa e correlação também com a um mínimo existencial, sendo que estes direitos surgiram e foram incorporados ao direito internacional como direitos à pessoa humana individualmente considerada.

O referido autor ressalta que os direitos sociais não são essencialmente coletivos, mas sim, são também individuais e tem conexão a diversos direitos fundamentais, neste sentido enfatiza Sarlet:

"(...) os direitos humanos e fundamentais, sejam eles civis e políticos, sejam eles sociais, econômicos e culturais (assim como ambientais, em certo sentido), são sempre direitos referidos, em primeira linha, à pessoa individualmente considerada, e é a pessoa (cuja dignidade é pessoal,

\footnotetext{
${ }^{14}$ AZURES, Jose Juan Gurria. Reseña "Los derechos fundamentales"de Antônio Enrique Pérez Luño. Boletin Mexicano de Derecho Comparado, vol. XL, núm. 120, septiembre-diciembre, 2007, pp. 1013-1021. Universidade Nacional Autónoma de México, Red, Realyc.org. p. 1015.

15 SARLET, Ingo Wolfgang. A eficácia do direitos fundamentais: uma teoria geral dos direitos fundamentais na perspectiva constitucional, $11^{\circ}$ edição, livraria do advogado, 2012, p.215
} 
TEIXEIRA, Elisângela Sampaio; FERRARI, Roseane. O papel do município na concretização dos direitos fundamentais sociais. Revista Eletrônica Direito e Política, Programa de Pós-Graduação Stricto Sensu em Ciência Jurídica da UNIVALI, Itajaí, v.10, n.3, 20 quadrimestre de 2015. Disponível em: www.univali.br/direitoepolitica - ISSN 1980-7791.

individual, embora socialmente vinculada e responsiva) o seu titular por excelência." ${ }^{16}$

No direito brasileiro os direitos sociais estão elencados no art. $6^{\circ}$ da Constituição Federal nos seguintes termos: "São direitos sociais a educação, a saúde, o trabalho, a moradia, o lazer, a segurança, a previdência social, a proteção à maternidade e à infância, a assistência aos desamparados, na forma desta Constituição".

Tais direitos estão exparsos em diversos pontos da Constituição Federal, pode-se citar como exemplo: o direito à educação art. $6^{\circ}$ e art. 205; o direito ao trabalho art 10, inciso IV e art. 170; direito ao lazer art. 0 217, § 30; direito à segurança art. 144; direito à proteção a maternidade e a infância art. 201, II e art. 203, I e II.

Explica Lurconvit que os direitos sociais são direitos prestacionais do Estado perante o indivíduo "(...) como assistência social, educação, saúde, cultura, trabalho, lazer, dentre outros." ${ }^{17} \mathrm{O}$ autor também coloca que a parte social complementa o indivíduo possibilita a participação e valoração da personalidade humana tão importante quanto preservar o indivíduo, trata-se de possibilidade de bem estar social.

Quanto ao objeto dos direitos sociais, Lurconvit ensina que "(...) os direitos sociais são voltados pela presença do Estado em ações voltadas à minoração dos problemas sociais, tendo por finalidade a melhoria de condições de vida aos hipossuficientes, visando à concretização da igualdade social. ${ }^{\prime 18}$

16 SARLET, Ingo Wolfgang. A eficácia do direitos fundamentais: uma teoria geral dos direitos fundamentais na perspectiva constitucional, $11^{\circ}$ edição, livraria do advogado, 2012, p.217.

17 LURCONVIT, Adriano dos Santos. A concretização dos direitos sociais: breves apontamento. XIII, n. 74, mar 2010. Rio Grande, RS. Âmbito Jurídico Comécio e Serviços de Informação Ltda. Disponível em: http://www.ambitojuridico.com.br/site/index.php?n_link=revista_artigos_leitura\&artigo_id=7277. Acesso em: 04/04/2015.

18 LURCONVIT, Adriano dos Santos. A concretização dos direitos sociais: breves apontamento. Rio Grande, RS, XIII, n. 74, mar 2010. Ambito Jurídico Comércio e Serviços de Informaçoes Ltda. Disponível em: http://www.ambito- 
TEIXEIRA, Elisângela Sampaio; FERRARI, Roseane. O papel do município na concretização dos direitos fundamentais sociais. Revista Eletrônica Direito e Política, Programa de Pós-Graduação Stricto Sensu em Ciência Jurídica da UNIVALI, Itajaí, v.10, n.3, 20 quadrimestre de 2015. Disponível em: www.univali.br/direitoepolitica - ISSN 1980-7791.

Quanto a realização dos direitos sociais é possível dizer que existem diversas maneiras, seja através de uma forma indireta, quando falta a norma, que possibilite ele acontecer, ou seja, pela omissão do poder público é possível pleitear a realização dos direitos sociais através de mandado de injunção ou da ação direta de inconstitucionalidade por omissão nos termos do artigo $5^{\circ}$, inciso LXXI e art. 103, § 20 respectivamente.

Outra é a fora direta e mais eficiente e imediata, é através da governabilidade e a criação de leis municipais que estimulem e possibilitem a concretização dos direitos sociais. É neste âmbito que enquadra-se a importância da conduta dos atores do município na efetividade de tais direitos.

\section{O MUNICÍPIO BRASILEIRO E AS POSSIBILIDADES DE CONCRETIZAÇÃO DOS DIREITOS SOCIAIS}

O município pode ser entendido como pessoa jurídica de Direito Interno, com limitação territorial determinada e organização política voltada aos interesses locais e comuns dos que naquela área convivem ${ }^{19}$ e possui como ente federativo autonomia política, administrativa, auto organizatória, legislativa e financeira ${ }^{20}$ garantida pela Constituição Federal que Ihe define a competência.

Portanto, o município ocupa um lugar de destaque na Federação Brasileira. Foi através da Constituição Federal de 1988 que recebeu status de ente federado tão importante quanto a União, os Estados Membros e o Distrito Federal. Aliás, não

juridico.com.br/site/index.php?n_link=revista_artigos_leitura\&artigo_id=7277. Acesso em: 04/04/2015

${ }^{19}$ COSTA, Nelson Nery. Direito Municipal Brasileiro. $6^{\circ}$ edição. Rio de Janeiro: Editora Forense, 2014, p.83.

20 CORRALO, Giovani da Silva. Município: autonomia na Federação Brasileira. $2^{\circ}$ edição. Curitiba: Juruá Editora, 2014, p. 175. 
TEIXEIRA, Elisângela Sampaio; FERRARI, Roseane. O papel do município na concretização dos direitos fundamentais sociais. Revista Eletrônica Direito e Política, Programa de Pós-Graduação Stricto Sensu em Ciência Jurídica da UNIVALI, Itajaí, v.10, n.3, 20 quadrimestre de 2015. Disponível em: www.univali.br/direitoepolitica - ISSN 1980-7791.

houve em nenhuma outra Constituição Brasileira as autonomias concedidas na constituição de 1988 oque, a partir de então, modificou o cenário brasileiro. ${ }^{21}$

A autonomia política concedida pela CF ao município brasileiro possibilita aos cidadãos a eleição de seu prefeito e vereadores (art. 54, art. 29, XIV, art. 38, II da (F), o que irá refletir na possibilidade de uma consciência cidadã pela escolha de seus candidatos e posteriormente a cobrança das realizações prometidas. A autonomia política possibilita a fiscalização da governança pública, visto que é presente na doutrina o entendimento da accountability vertical e horizontal. A primeira é realizada pelo povo nos processos eleitorais, nos quais os agentes políticos são julgados e avaliados. A segunda é realizada pelos órgãos e instituições que possuem esta atribuição, como é o caso exemplificativo dos tribunais de contas. ${ }^{22}$

Ademais, o município possui competência para legislar - autonomia legislativa sobre assuntos de interesse local "devendo prevalecer sobre as competências federais e estaduais"23 e nos termos do art. 30, I e II da CF.

Sob a óptica dos direitos sociais pode citar-se como exemplo que compete ao município promover programas de construção de moradias e a melhoria das condições habitacionais e de saneamento básico, art. 23, IX, CF.

Costa também destaca que, conforme o artigo acima citado, o município deve "combater as causas da pobreza e os fatores de marginalização, promovendo a integração social dos setores desfavorecidos". O autor diferencia a pobreza da marginalização, afirmando que aquela " é um reflexo de uma política histórica de concentração de rendas, que faz com que grande parte da população viva em condições mínimas de sobrevivência para si e sua descendência "24

\footnotetext{
${ }^{21}$ COSTA, Nelson Nery. Direito Municipal Brasileiro, 2014, p.99.

22 BENTO, Leonardo Valles. Governança e governabilidade na reforma do Estado: entre eficiência e democratização. Barueri: Manolo, 2003, p. 103-105.

${ }^{23}$ COSTA, Nelson Nery. Direito Municipal Brasileiro, 2014, p.85.

${ }^{24}$ COSTA, Nelson Nery. Direito Municipal Brasileiro, 2014, p.93
} 
TEIXEIRA, Elisângela Sampaio; FERRARI, Roseane. O papel do município na concretização dos direitos fundamentais sociais. Revista Eletrônica Direito e Política, Programa de Pós-Graduação Stricto Sensu em Ciência Jurídica da UNIVALI, Itajaí, v.10, n.3, 20 quadrimestre de 2015. Disponível em: www.univali.br/direitoepolitica - ISSN 1980-7791.

Já a marginalização é um processo mais grave, é a total perda da cidadania, as pessoas vivem em condições miseráveis ${ }^{25}$, a margem da ordem social e numa perceptível falta de dignidade. Estas pessoas não conseguem sair desta condição sem políticas públicas eficientes e bem coordenadas que possibilitem consciência e perspectiva de uma melhora da sua condição sócio econômica.

Obviamente é a autonomia financeira que possibilitará todas as outras autonomias se realizem. E, a falta de recursos dos municípios brasileiros faz com que ele dependa muito dos repasses da União e dos Estados Membros. Por outro lado, cabe ao administrador municipal a busca de recursos e prioridade para administrar esses recursos de forma a concretizar os direitos sociais e incluí-los em suas políticas públicas.

Por outro lado, o município também deve proporcionar incentivos com a finalidade de atrair e fomentar empreendimentos que venham a gerar renda e emprego, visando assim, o desenvolvimento socioeconômico do município. A legislação municipal pode prever doação e cessão de uso de áreas de terras; subsídio no pagamento de juros de financiamentos; isenção de tributos; pagamento de aluguel; realização de serviços de terraplanagem e infraestrutura.

Corralo $^{26}$ ensina que o município brasileiro possui autonomia administrativa (art. 30, III a IX, da CF) que trata da possibilidade do ente municipal gerenciar os serviços locais os quais os interesses são maiores do que os interesses do que o federal ou estadual. Há possibilidade de proporcionar serviços públicos de qualidade aos cidadãos, possibilidade de polícia administrativa e fomento de atividades de caráter administrativo.

Uma boa governança pública, consciente das autonomias municipais e conhecedora de tais competências e responsabilidades possibilita ao gestor e legislador público municipal concretizar direitos sociais, pois conforme demonstra Corralo:

\footnotetext{
${ }^{25}$ COSTA, Nelson Nery. Direito Municipal Brasileiro, 2014, p.93

${ }^{26}$ CORRALO, Giovani da Silva. Município: autonomia na Federação Brasileira, 2014, p. 191.
} 
TEIXEIRA, Elisângela Sampaio; FERRARI, Roseane. O papel do município na concretização dos direitos fundamentais sociais. Revista Eletrônica Direito e Política, Programa de Pós-Graduação Stricto Sensu em Ciência Jurídica da UNIVALI, Itajaí, v.10, n.3, 20 quadrimestre de 2015. Disponível em: www.univali.br/direitoepolitica - ISSN 1980-7791.

\begin{abstract}
"A Constituição Brasileira de 1988 resguardou um plexo de autonomia sem similar na história brasileira, juntamente com a consideração do Município como um ente partícipe do pacto federativo. Tal disposição encontra fundamento nos princípios basilares do federalismo, especialmente os princípios republicanos, não-concentração, Estado Democrático de Direito, liberdade, democracia, pluralismo e subsidiariedade, além de encontrar sintonia com a própria organização federativa." 27
\end{abstract}

Foi bem vinda para a sociedade brasileira tal determinação na Constituição Federal tendo em vista que é o município o ente que engloba diretamente todos os problemas sociais dos cidadãos, é nele que acontece a possibilidade de relação mais próxima e direta com as pessoas.

Complementa ainda o referido autor que "a efetivação da autonomia municipal em toda a sua amplitude é essencial para a efetivação do Estado Democrático de Direito e para a efetivação dos direitos fundamentais."

O município exerce um papel fundamental na concretização dos direitos sociais através de políticas públicas eficientes. Políticas Públicas, segundo Teixeira são "(...) diretrizes, princípios norteadores de ação do poder público; regras e procedimentos para as relações entre poder público e sociedade, mediações entre atores da sociedade e do Estado"28.

Ou seja, é o momento em que se pensa como a administração definirá o que é mais importante para aquela comunidade. Fato que se concretiza através de políticas públicas, leis, programas e linhas de financiamento, sempre visando possibilidade de melhoria da qualidade de vida das pessoas a à diminuição das desigualdades sociais. Por isso, é importante refletir as autonomias municipais, boa governança e concretização dos direitos sociais.

\footnotetext{
27 CORRALO, Giovani da Silva. Município: autonomia na Federação Brasileira, 2014, p. 244.

28 TEIXEIRA, Elenaldo Celso. O papel das políticas públicas no desenvolvimento local e na transformação da realidade. AATR Bahia, 2002, Disponível em: http://www.escoladebicicleta.com.br/politicaspublicas.pdf, acesso em $1^{0}$ de abril de 2015.
} 
TEIXEIRA, Elisângela Sampaio; FERRARI, Roseane. O papel do município na concretização dos direitos fundamentais sociais. Revista Eletrônica Direito e Política, Programa de Pós-Graduação Stricto Sensu em Ciência Jurídica da UNIVALI, Itajaí, v.10, n.3, 20 quadrimestre de 2015. Disponível em: www.univali.br/direitoepolitica - ISSN 1980-7791.

Os controles dos indicadores sociais mínimos dos municípios são feitos no Brasil através do Instituto Brasileiro de Geografia e Estatística (IBGE), sendo este o órgão responsável pela produção das informações que integram o sistema de indicadores sociais, é estes órgão que irá mostrar informações relevantes da população brasileira. No entanto, afirma Oliveira et al. "que existem algumas agencias estaduais de estatísticas, bem como Ministérios e Secretarias que também realizam pesquisas e analise desses indicadores." ${ }^{29}$ Estes indicadores recolhidos por estes órgãos irão compor o Índice de Desenvolvimento Humano (IDH) analisados pela Organização das Nações Unidas (ONU).

Portanto, o controle estatístico existe, é importante, e faz com que sejam definidas metas aos entes federados e sirvam não só como forma de transparência administrativa como também receber mais incentivos financeiros futuros.

Outro fator determinante que objetiva conduzir a aplicação dos recursos municipais nos direitos sociais é a Lei de Responsabilidade Fiscal n 101 de 04 de maio de 2000. Esta lei objetiva conduzir à transparência e parâmetros a serem seguidos na aplicação dos recursos financeiros dos Estados e Municípios.

Trabalho interessante foi realizado por Oliveria $^{30}$, et al. Os autores pesquisaram 184 municípios do Estado do Ceará, devido ao fato desta região ter logrado o $22^{\circ}$ lugar do Brasil quanto ao Índice de Desenvolvimento Humano, estando entre os piores estados brasileiros nesse aspecto. Colheram dados do período de 2004 à 2007.Propuseram-se a analisar quais as implicações da Lei de Responsabilidade Fiscal sobre os indicadores sociais dos municípios limitados na pesquisa.

\footnotetext{
${ }^{29}$ OLIVEIRA, Fabiana Helcias. PETER, Maria da Glória Arraias. MENESES, Anelise Florêncio. Lei de responsabilidade fiscal: implicações nos indicadores sociais municipais, XV Congresso USP de Controladoria e Contabilidade e XII Congresso USP de Iniciação Científica em Contabilidade, São Paulo, 2014. 204 Disponível em: http://www.congressousp.fipecafi.org/web/artigos102010/252.pdf. Acesso em 05/04/2015.

30 OLIVEIRA, Fabiana Helcias. PETER, Maria da Glória Arrais. MENESES, Anelise Florencio.

Lei de responsabilidade fiscal: implicações nos indicadores sociais municipais. $10^{\circ}$ Congresso USP de Controladoria e Contabilidade. Artigo no 252. São Paulo: USP, 2010. Disponível em: http://www.congressousp.fipecafi.org/web/artigos102010/252.pdf. Acesso em 04/04/2015.
} 
TEIXEIRA, Elisângela Sampaio; FERRARI, Roseane. O papel do município na concretização dos direitos fundamentais sociais. Revista Eletrônica Direito e Política, Programa de Pós-Graduação Stricto Sensu em Ciência Jurídica da UNIVALI, Itajaí, v.10, n.3, 20 quadrimestre de 2015. Disponível em: www.univali.br/direitoepolitica - ISSN 1980-7791.

Concluíram que os gestores vinham cumprindo com os limites estabelecidos pela LRF e quanto maior o índice de responsabilidade fiscal, ou seja, quanto mais ele cumpre com a LRF, melhor estava o desempenho do gestor na aplicação dos recursos públicos e nos investimentos sociais, referentes a educação e saúde.

Ou seja, o trabalho concluiu que as variações nos índices de responsabilidade fiscal impactam na evolução dos indicadores sociais da educação e saúde, uma vez que quanto melhor o índice de responsabilidade fiscal, ou seja, quanto mais o gestor se aproxima do índice máximo melhor foi seu desempenho quanto ao atendimento das demandas sociais.

A autora complementa dizendo que trabalho conclui que a LRF tem contribuído para o controle dos gastos fiscais, a partir de imposição de limite aos gestores, pois se não houvesse tal regulamentação, o descaso com os investimentos sociais poderiam ser aumentado, em virtude da falta de recursos e do aumento da divida publica.

Pode-se dizer então que a LRF contribui para que os recursos, mesmo que escassos nos municípios não só cearenses como em todo o Brasil, sejam aplicados na concretização dos direitos sociais.

No entanto, segundo Canotilho "(...) o problema actual dos 'direitos sociais' ou 'direitos a prestações em sentido estrito' está em 'levarmos a sério' o reconhecimento de direitos como o direito ao trabalho, o direito à saúde, o direito à educação, o direito à cultura, o direito ao ambiente ${ }^{\prime \prime 31}$.

Portanto, o ente municipal através de seu parlamento e de sua governança tem o dever de proporcionar as pessoas planos políticos que possibilitem a diminuição das desigualdades sociais, o que deveria ser sempre prioridade da boa administração pública.

E ainda, ressaltando a importância da necessidade da fluidez da governança e participação cidadã, Bauman bem explica que devemos recordar, antes de mais

${ }^{31}$ CANOTILHO, J. J. G. Estudos sobre direitos fundamentais. Coimbra: Coimbra, 2004. p. 51. 
TEIXEIRA, Elisângela Sampaio; FERRARI, Roseane. O papel do município na concretização dos direitos fundamentais sociais. Revista Eletrônica Direito e Política, Programa de Pós-Graduação Stricto Sensu em Ciência Jurídica da UNIVALI, Itajaí, v.10, n.3, 20 quadrimestre de 2015. Disponível em: www.univali.br/direitoepolitica - ISSN 1980-7791.

nada, que as "cidades, nas quais vive atualmente mais da metade do gênero humano, são de certa maneira os depósitos onde se descarregam os problemas criados e não resolvidos no espaço global" ${ }^{\prime 32}$, neste sentido, a governança local torna-se imprescindível para dar vazão aos problemas sociais utilizando-se de uma boa governança local através do uso eficiente das autonomias proporcionadas pela Constituição Federal.

Os governantes municipais para concretizarem os direitos sociais também dispõe da possibilidade de ações afirmativas para promover a inclusão social. Coloca Luconvit que ações afirmativas "constituem em medidas especiais que têm por objetivo acelerar o processo de igualdade, com o alcance da isonomia não apenas formal, mas, substantiva por parte dos, se assim podemos dizer, "grupos vulneráveis" ${ }^{\prime 33}$. São exemplos de ações afirmativas: o trabalho da mulher (artigo 70, inciso $X X)$, a reserva de mercado de cargos públicos para as pessoas portadoras de deficiência (artigo 37, inciso VIII).

Complementa Sacchetto et al. que as ações afirmativas são:

"(...) politicas de inclusão realizadas por entidades públicas, privadas e outros órgãos, competentes, que buscam a igualdade, do equilíbrio entre oportunidades e que precisa ser organizada, de forma a se alcançar todos os níveis. 0 Estado tem papel importante na busca desse objetivo, através de suas propostas de inclusão social e exigindo aos demais, a busca da igualdade através das ações afirmativas." ${ }^{\prime 34}$

Pode-se citar como exemplo de direitos sociais concretizados em nível municipal através de ações afirmativas: Lei 7.511/2007 do Município de Florianópolis que busca promover a igualdade racial e defesa dos que sofrem preconceito ou

32 BAUMAN, Zygmunt. Confiança e medo na cidade. Rio de Janeiro: Jorge Zahar. 2009, p. 03.

33 LURCONVIT, Adriano dos Santos. A concretização dos direitos sociais: breves apontamento. XIII, n. 74, mar 2010. Rio Grande, RS. Âmbito Jurídico Comércio e Serviços de Informação Ltda. Disponível em: http://www.ambitojuridico.com.br/site/index.php?n_link=revista_artigos_leitura\&artigo_id=7277. Acesso em: 04/04/2015.

${ }^{34}$ SACCHETTO, Karen Kaufmann et al. Educação especial: Legislação que a respalda e ações afirmativas. Cadernos de Pós-Graduação em Distúrbios do Desenvolvimento, São Paulo, v.11, n.1, p. 47. p. 37-51, 2011. ISSN 1809-4139. Disponível em: http://www.mackenzie.br/fileadmin/Graduacao/CCBS/PosGraduacao/Docs/Cadernos/Volume_11/ Kaufmann-Sacchetto_et_al_v_11_n_1_2011artigo_1.pdf. Acesso em: 05/04/2015. 
TEIXEIRA, Elisângela Sampaio; FERRARI, Roseane. O papel do município na concretização dos direitos fundamentais sociais. Revista Eletrônica Direito e Política, Programa de Pós-Graduação Stricto Sensu em Ciência Jurídica da UNIVALI, Itajaí, v.10, n.3, 20 quadrimestre de 2015. Disponível em: www.univali.br/direitoepolitica - ISSN 1980-7791.

discriminação em função de sexo, raça ou cor, através da inserção e educação social. Lei 12.400/2012 do Município de João Pessoa que possui como objetivo a formulação de programas para proteção da população LGBT, comunidade negras, quilombolas e ciganos. Lei orgânica do Município de São Paulo que em seus artigos 203, IV, 204, IV e 206, $\S 1^{\circ}$ e $2^{\circ}$ declara que o município deve promover a educação inclusiva a acesso a serviços educacionais de crianças com deficiência múltiplas.

No município de Passo Fundo, RS, foi implantado, no ano de 2014, o projeto "farmácia mais perto" que proporciona a descentralização da farmácia do município que levada aos bairros através de uma unidade móvel que atende cerca de quarenta bairros do município, proporcionando um acesso mais facilitado a quem precisa de medicamentos ${ }^{35}$. Quanto a este ultimo exemplo pode-se afirmar como relevante cumprimento do direito fundamental social o direito à saúde previsto no art. $6^{\circ}$, da CF, complementado pelo artigo 196 da $\mathrm{CF}^{36}$.

\section{CONSIDERAÇÕES FINAIS}

Nestas últimas três décadas, possibilitou-se dentro do estado democrático de direito brasileiro a autonomia municipal, ou seja, uma descentralização do poder para que o Estado possa chegar mais próximo ao cidadão. Obviamente os recursos são escassos, ficando a autonomia financeira em muito a desejar. No entanto, não se pode negar que existem exemplos eficientes de boa governança pública em diversos municípios do Brasil.

\footnotetext{
35 Prefeitura Municipal de Passo Fundo. Farmácia mais perto: programa distribuiu mais de 600 mil comprimidos em um ano. Saúde. Departamento de Comunicação Social. Assessoria de imprensa. Publicado em: 01/04/2015, 02:04. Disponível em: http://pmpf.rs.gov.br/pagina_interna.php?t $=19 \& \mathrm{c}=10848 \& \mathrm{p}=1212 \& \mathrm{a}=2 \& \mathrm{pm}=$. Acesso em: 05/04/2015.
}

${ }^{36}$ BRASIL. Constituição da República Federativa do Brasil, de 05 de outubro de 1988. Disponível em: http://www.planalto.gov.br/ccivil_03/constituicao/constituicao.htm. Acesso em: 22 de setembro de 2014. 
TEIXEIRA, Elisângela Sampaio; FERRARI, Roseane. O papel do município na concretização dos direitos fundamentais sociais. Revista Eletrônica Direito e Política, Programa de Pós-Graduação Stricto Sensu em Ciência Jurídica da UNIVALI, Itajaí, v.10, n.3, 20 quadrimestre de 2015. Disponível em: www.univali.br/direitoepolitica - ISSN 1980-7791.

A lei de responsabilidade fiscal trouxe consigo a exigência da transparência e o cumprimento de metas como forma de pressionar os entes locais a cumprirem com alguns direitos sociais. Esta transparência exigida pela lei de responsabilidade fiscal vem ao encontro da ferramenta de accountability uma das características da boa governança municipal.

Neste diapasão, direitos sociais e autonomia municipal imbricam-se para dar concretude ao Estado Democrático de Direito consubstanciado na Constituição de 1988.

O município deve e tem possibilidade de fazer politicas públicas voltadas a concretização dos direitos sociais, essa é a função primordial deste ente estatal, pois é ele que conhece as necessidades e interesse local. Isso só é possível através de uma boa governança pública pautada na transparência, no controle do nível dos endividamentos e gastos públicos, fiscalização por parte dos cidadãos e pelo conhecimento jurídico das autonômias municipais.

\section{REFERÊNCIAS DAS FONTES CITADAS:}

AZURES, Jose Juan Gurria. Reseña "Los derechos fundamentales"de Antônio Enrique Pérez Luño. Boletin Mexicano de Derecho Comparado, vol. XL, núm. 120, septiembre-diciembre, 2007, pp. 1013-1021. Universidade Nacional Autónoma de México, Red, Realyc.org.

BASTOS, Cleverson Leite. KELLER, Vicente. Aprendendo a aprender: introdução à metodologia científica. Petrópolis, RJ: Editora Vozes, 2008.

BAUMAN, Zygmunt. Confiança e medo na cidade. Rio de Janeiro: Editora Jorge Zahar. 2009.

BERTRAMELLO, Rafael. Os direitos sociais: conceito, finalidade e teorias. Jusbrasil. Jun. $2014 . \quad$ Disponível em: http://rafaelbertramello.jusbrasil.com.br/artigos/121943093/os-direitos-sociaisconceito-finalidade-e-teorias. Acesso 02 de abril de 2015. 
TEIXEIRA, Elisângela Sampaio; FERRARI, Roseane. O papel do município na concretização dos direitos fundamentais sociais. Revista Eletrônica Direito e Política, Programa de Pós-Graduação Stricto Sensu em Ciência Jurídica da UNIVALI, Itajaí, v.10, n.3, 20 quadrimestre de 2015. Disponível em: www.univali.br/direitoepolitica - ISSN 1980-7791.

BENTO, Leonardo Valles. Governança e governabilidade na reforma do Estado: entre eficiência e democratização. Barueri: Manolo, 2003, p. 103105.

BRASIL. Constituição da República Federativa do Brasil, de 05 de outubro de $1988 . \quad$ Disponível em: http://www.planalto.gov.br/ccivil_03/constituicao/constituicao.htm. Acesso em: 22 de setembro de 2014.

- Lei orgainica do município de São Paulo. Disponível em <http://portalsme.prefeitura.sp.gov.br/Documentos/BibliPed/TextosLegais/Legisl acaoEducacional/LeiOrganicaMunicipioSaoPaulo.pdf> Acesso em: 15 de janeiro de 2015.

CANOTILHO, José Joaquim Gomes. LEITE, José Rubens Morato. Direito constitucional ambiental brasileira. 3. ed. São Paulo, SP: Editora Saraiva, 2010, p.215.

CANOTILHO, José Joaquim Gomes. Estudos sobre direitos fundamentais. Coimbra: Coimbra, 2004. p. 51.

CORRALO, Giovani da Silva. Município: autonomia na Federação Brasileira. $2^{\circ}$ edição. Curitiba: Juruá Editora, 2014, p. 175.

COSTA, Nelson Nery. Direito Municipal Brasileiro. $6^{\circ}$ edição. Rio de Janeiro: Editora Forense, 2014, p.83.

PISARELLO, Geraldo. Los derechos sociales y sus garantías. Elementos para una reconstrucción. Madrid: Editorial Trotta, 2007.

GUSTIN, Miracy Barbosa de Souza. DIAS, Maria Tereza Fonseca. (Re)pensando a pesquisa jurídica: teoria e prática. Belo Horizonte, $\mathrm{BH}$ : Editora Del Rey, 2010, p.106.

Prefeitura Municipal de Passo Fundo. Farmácia mais perto: programa distribuiu mais de 600 mil comprimidos em um ano. Saúde. Departamento de Comunicação Social. Assessoria de imprensa. Publicado em: 01/04/2015, 02:04. Disponível http://pmpf.rs.gov.br/pagina_interna.php?t $=19 \& \mathrm{c}=10848 \& \mathrm{p}=1212 \& \mathrm{a}=2 \& \mathrm{pm}=$. Acesso em: 05/04/2015.

Revolução industrial. Portal de comunicação professore e aluno - PRAL. Porto Alegre, RS. Disponível em: http://www.sohistoria.com.br/resumos/revolucaoindustrial.php. Acesso 05/04/2015. 
TEIXEIRA, Elisângela Sampaio; FERRARI, Roseane. O papel do município na concretização dos direitos fundamentais sociais. Revista Eletrônica Direito e Política, Programa de Pós-Graduação Stricto Sensu em Ciência Jurídica da UNIVALI, Itajaí, v.10, n.3, 20 quadrimestre de 2015. Disponível em: www.univali.br/direitoepolitica - ISSN 1980-7791.

LURCONVIT, Adriano dos Santos. A concretização dos direitos sociais: breves apontamento. XIII, n. 74, mar 2010. Rio Grande, RS. Âmbito Jurídico Comécio e Serviços de Informação Ltda. Disponível em: http://www.ambitojuridico.com.br/site/index.php?n_link=revista_artigos_leitura\&artigo_id=7277. Acesso em: 04/04/2015.

OLIVEIRA, Fabiana Helcias. PETER, Maria da Glória Arrais. MENESES, Anelise Florencio.

Lei de responsabilidade fiscal: implicações nos indicadores sociais municipais. $10^{\circ}$ Congresso USP de Controladoria e Contabilidade. Artigo no 252. São Paulo: USP, 2010. Disponível em: http://www.congressousp.fipecafi.org/web/artigos102010/252.pdf. Acesso em 04/04/2015.

SACCHETTO, Karen Kaufmann et al. Educação especial: Legislação que a respalda e ações afirmativas. Cadernos de Pós-Graduação em Distúrbios do Desenvolvimento, São Paulo, v.11, n.1, p. 47. p. 37-51, 2011. ISSN 1809-4139. Disponível em: http://www.mackenzie.br/fileadmin/Graduacao/CCBS/PosGraduacao/Docs/Cader nos/Volume_11/Kaufmann-Sacchetto_et_al_v_11_n_1_2011artigo_1.pdf. Acesso em: 05/04/2015.

SARLET, Ingo Wolfgang. A eficácia do direitos fundamentais: uma teoria geral dos direitos fundamentais na perspectiva constitucional, $11^{\circ}$ edição, livraria do advogado, 2012.

TEIXEIRA, Elenaldo Celso. $\mathbf{0}$ papel das políticas públicas no desenvolvimento local e na transformação da realidade. AATR Bahia, 2002, Disponível em: http://www.escoladebicicleta.com.br/politicaspublicas.pdf, acesso em $1^{\circ}$ de abril de 2015.

Submetido em: Abril/2015

Aprovado em: Junho/2015 